\title{
Theoretical Deduction of the Optimum Tilt Angles for Small-Scale Linear Fresnel Reflectors
}

\author{
Arsenio Barbón ${ }^{1} \mathbb{D}$, Covadonga Bayón-Cueli ${ }^{2}$, José A. Fernández Rubiera ${ }^{1}$ (D) and Luis Bayón ${ }^{3, *}$ \\ 1 Department of Electrical Engineering, University of Oviedo, 33203 Gijón, Spain; barbon@uniovi.es (A.B.); \\ fernandezrjose@uniovi.es (J.A.F.R.) \\ 2 Polytechnic School of Engineering of Gijón, University of Oviedo, 33203 Gijón, Spain; UO229809@uniovi.es \\ 3 Department of Mathematics, University of Oviedo, 33203 Gijón, Spain \\ * Correspondence: bayon@uniovi.es
}

\begin{abstract}
A theoretical justification and computation of the optimum values of the two longitudinal tilt angles of a small-scale linear Fresnel reflector is provided. The optimum angle of the mobile structure is proved to be half the latitude of the geographic location, while the optimum angle of the secondary reflector system is proved to be equal to that latitude. Brute-force verification is carried out for five EU cities, each in one of the five European climate zones.
\end{abstract}

Keywords: small-scale linear Fresnel reflector; optimum tilt angles; urban applications

Citation: Barbón, A.; Bayón-Cueli, C.; Fernández Rubiera, J.A.; Bayón, L. Theoretical Deduction of the Optimum Tilt Angles for Small-Scale Linear Fresnel Reflectors. Energies 2021, 14, 2883. https://doi.org/ $10.3390 /$ en14102883

Academic Editor: Wojciech Budzianowski

Received: 25 April 2021

Accepted: 14 May 2021

Published: 17 May 2021

Publisher's Note: MDPI stays neutral with regard to jurisdictional claims in published maps and institutional affiliations.

Copyright: (c) 2021 by the authors. Licensee MDPI, Basel, Switzerland. This article is an open access article distributed under the terms and conditions of the Creative Commons Attribution (CC BY) license (https:/ / creativecommons.org/licenses/by/ $4.0 /)$.

\section{Introduction}

Small-scale linear Fresnel reflectors (SSLFRs) are a type of solar collector of recent development with a high potential in the building sector. Buildings in the European Union (EU) consumed more than $27 \%$ of the total energy used in 2017 , most of it (84\%) coming from fossil fuels [1,2]. The 2030 Agenda aims to reduce greenhouse emissions in the EU to $40 \%$ of the 1990 reference level [3]. In their review of solar collectors and their application in buildings, Buker et al. [4] assert that concentrating collectors (among which parabolic troughs and SSLFRS) are quite suitable and practical.

Applications of SSLFRs in urban settings are manifold: domestic water heating [5], heating/cooling systems [6], absorption of cooled air in Solar-GAX cycles [7], absorption cooling systems [8], electricity generation [9], concentrating photovoltaics [10], and daylighting systems [11].

The typical size of a mirror field in large-scale LFRs is 25 (m) (width) and 1000 (m) (length), too large to allow tilting. On the other hand, small-scale LFRs allow geometric modifications (as tilting), which increase the energy reaching the absorber tube. In previous works, the authors [12-14] present a design with longitudinal tilt of some components (rows of mirrors, absorber tube, or both). In [14], numerical simulations are carried out, including a study of the relation between the energy-to-area ratio $(E A R)$ and the longitudinal tilts, but no theoretical study is performed to compute the optimum values. Other designs [15] allow for vertical motion of the mirrors on the horizontal plane. On a different note, Pulido et al. [16] propose a value for the optimal inclination of the rows of mirrors and absorber tube, in the north-south direction, in Tabernas, Almeria (Spain), but they do not account for two key longitudinal parameters: the position and length of the absorber tube. On top of that, the area required for the SSLFR installation is not considered either.

An SSLFR consists of the following systems [17]: fixed structure, mobile structure, primary and secondary reflector systems, and transmission and tracking systems. The fixed structure supports the mobile one and the secondary reflector system. The primary reflector system is supported by the mobile structure, which can be tilted longitudinally. The primary reflector system consists of an array of stretched mirrors, which rotate on the north-south axis following the Sun's motion. The secondary reflector system can also be 
tilted longitudinally and is placed at a certain height above the primary one. It is composed of an absorber tube, a receiver cavity, insulation, and a glass cover. The absorber tube is encased in the receiver cavity, which is sealed with the glass cover and with silicon rubber beading. Figure 1 shows the simplified schematics of a generic SSLFR and its parameters.

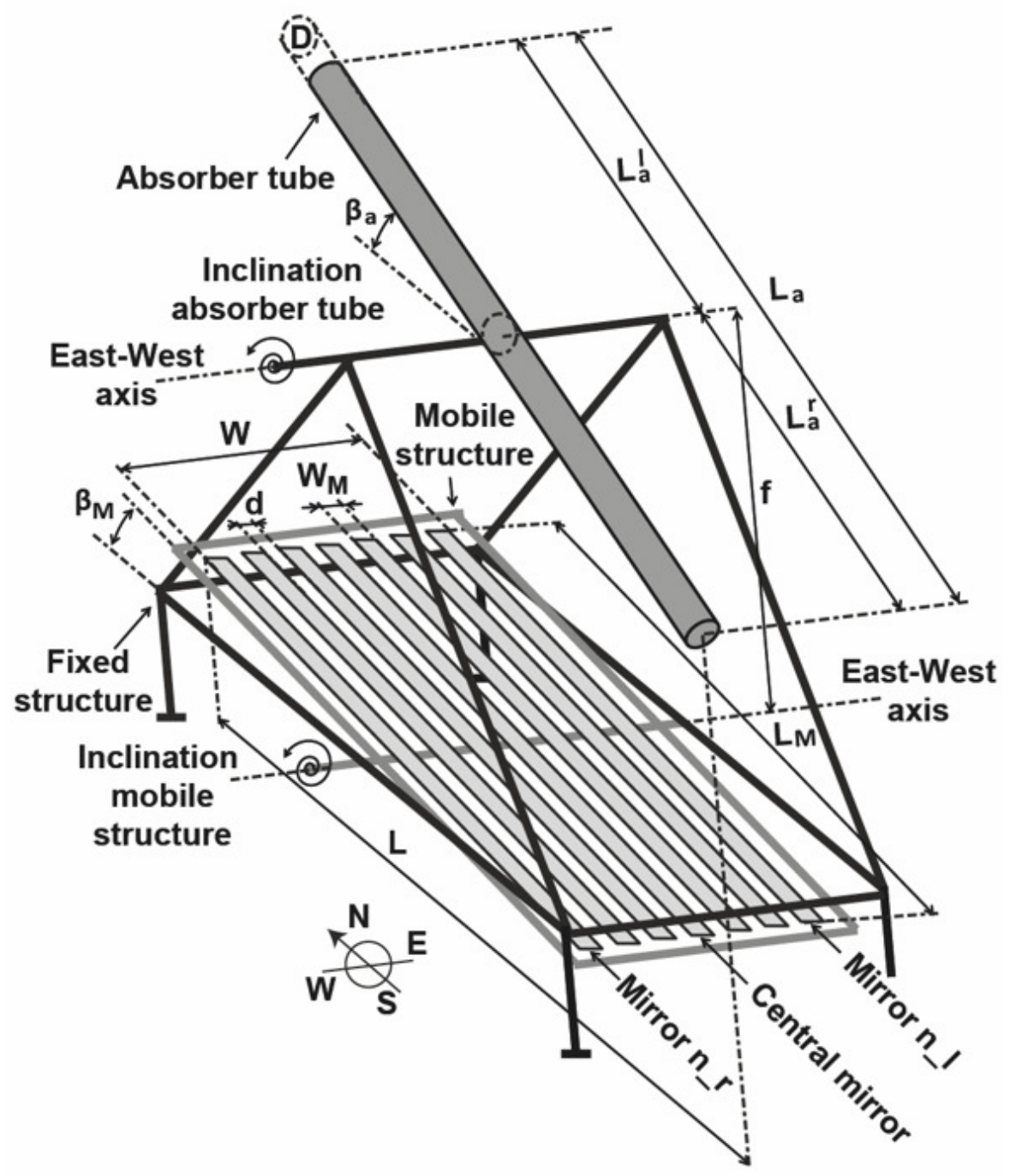

Figure 1. Simplified schematics of a generic SSLFR.

In this work, we analyze the longitudinal inclination of the mobile structure and the secondary reflector system of an SSLFR. This requires knowing all the parameters involved in its operation. The reader is referred to [12-14] for detailed analyses of these parameters, which we collect in the Annex, for the sake of clarity and completeness.

The performance of an SSLFR is greatly (and mainly) influenced by the longitudinal tilt angles of the reflector systems. Their variation produces changes in the amount of solar radiation reaching the absorber tube and the area required for its installation in urban applications. In a recent work [14], the authors have studied this influence in urban applications and their effect on other parameters: the energy absorbed by the absorber tube, the $E A R$, and the primary cost. This work covers the influence of the latitude on the results we have obtained.

The empirical results in [14] provided general patterns, but there was one which was especially remarkable: the maximum of the $E A R$ was always obtained for a certain combination of tilt angles of the reflector systems.

The contributions of this work are the following: 
(i) A theoretical justification of the relationship between the optimum longitudinal tilt angles of an SSLFR and the value of the EAR for any location.

(ii) The calculation of the optimal tilt angle of the mobile structure minimizing the area required for the installation.

(iii) The calculation of an optimal tilt angle of the secondary reflector system maximizing the annual energy absorbed by the absorber tube.

(iv) A detailed analysis, which estimates the influence of those longitudinal tilt angles on the EAR.

Our method is based on the fact that the rays reflected by the rows of mirrors in the longitudinal direction are vertical at solar noon (see Figure 5).

This paper is organized as follows. Section 2 presents the problem under study, while the theoretical justification is outlined in Section 3. In Section 4, a brute-force search algorithm is used to verify the proposed equations, and finally, Section 5 summarizes the main results and conclusions. An Annex includes all the formulas obtained in previous works in order to facilitate the reading of this work.

\section{Overview}

The final aim of this work is to maximize the ratio of total energy $E$ (MWh) absorbed by the absorber tube over the area $A\left(\mathrm{~m}^{2}\right)$ required for the SSLFR installation, that is, the $E A R$ :

$$
E A R=\frac{\sum_{n_{d}=1}^{365}\left[\int_{0}^{24}\left(\sum_{i=0}^{2 \cdot n} D N I^{n_{d}}\left(T_{S}\right) \cdot \eta_{o p t} \cdot I A M_{i}^{n d}\left(T_{S}\right) \cdot A_{e f f i}^{n_{d}}\left(T_{S}\right)\right) d T_{S}\right]}{A}
$$

where $D N I$ is the direct normal irradiance, $\eta_{\text {opt }}$ is the optical efficiency, IAM is the incidence angle modifier, $A_{e f f i}^{n_{d}}$ is the effective area illuminated on the absorber tube by mirror $i, n$ is the number of mirrors at each side of the central mirror, $T_{S}$ is the solar time, $n_{d}$ is the ordinal of the day.

The formulas used for computing each of the elements of (1) are included in the Annex. Notice that, among all the variables affecting the $E A R$, we are, in this work, only interested in the longitudinal tilt angles of the mobile structure and the secondary reflector system, i.e., $\beta_{M}$ and $\beta_{a}$. We remark that they only appear in the formulas for the reflector length, $L$, and the total illuminated length of the absorber tube, $l_{a}$.

On the one hand, the reflector length $L$ can be computed using one of three laws (Equations (23)-(25)): depending on whether the projection of the absorber tube lies inside the projection of the primary field of mirrors, or whether it overflows to the left or to the right. The lengths $L_{a}^{l}$ and $L_{a}^{r}$ (the left and right length, respectively, of the absorber tube) appear in those laws. These quantities are design parameters of the SSLFR and calculated, in our case, by means of an algorithm presented in [12], which computes the length and place of the absorber tube, maximizing the annual energy obtained for each pair of values $\beta_{M}$ and $\beta_{a}$.

On the other hand, the total illuminated length of the absorber tube $l_{a}$ is calculated from its left $\left(l_{a}^{l}\right)$, right $\left(l_{a}^{r}\right)$ components, whose values are given by (31) and (32).

Obviously, there is a relation between the pairs $L_{a}^{l}$ and $L_{a}^{r}$ (which are design values) and $l_{a}^{l}$ and $l_{a}^{r}$, (true values of illuminated lengths), but it is important to realize that one cannot compute one from the other explicitly. Therefore, it is also impossible to obtain a closed formula $E A R\left(\beta_{M}, \beta_{a}\right)$. If we could do so, we could state the problem as a non-linear programming optimization problem:

$$
\left.\left.\begin{array}{l}
\max _{\beta_{M}, \beta_{a}} \operatorname{EAR}\left(\beta_{M}, \beta_{a}\right) \\
g\left(\beta_{M}, \beta_{a}\right) \leq 0 \\
\beta_{M} \in \mathbb{R}, \beta_{a} \in \mathbb{R}
\end{array}\right\} \rightarrow \begin{array}{l}
\max _{M} \operatorname{Ea} \beta_{a}\left(\beta_{M}, \beta_{a}\right) \\
\beta_{M}^{\min } \leq \beta_{M} \leq \beta_{M}^{\max } \\
\beta_{a}^{\min } \leq \beta_{a} \leq \beta_{a}^{\max }
\end{array}\right\}
$$


with no equality restrictions $h\left(\beta_{M}, \beta_{a}\right)=0$ in the independent variables and with only inequality restrictions $g\left(\beta_{M}, \beta_{a}\right) \leq 0$ in each of the variables, separately, as box constraints. One could use, in this case, the classical Karush-Kuhn-Tucker (KKT) conditions to find necessary conditions for the optimum solution of the problem. However, as explained above, we need to use a different approach.

The maximum $\operatorname{EAR}\left(\beta_{M}, \beta_{a}\right)$ value lies in a specific subset of $\mathbb{R}^{2}$ : a bounded rectangular region, delimited by the minimum and maximum values of $\beta_{M}$ and $\beta_{a}$. We shall approach the problem in two stages: as our objective is to maximize $E A R$, which is given by Equation (1), we first minimize $A$, and next, we maximize $E$.

Apart from the assumptions in previous works, the following one is made in the present study: the area required for the SSLFR installation cannot exceed $10\left(\mathrm{~m}^{2}\right)$, and $\beta_{M}$ and $\beta_{a}$ must be between 0 and $\lambda$ [14], so that the box constraints are: $\beta_{M}^{\min }=\beta_{a}^{\min }=0$ and $\beta_{M}^{\max }=\beta_{a}^{\max }=\lambda$. Former calculations have proved that for angles greater than $\lambda$, the required surface area is much larger than those $10\left(\mathrm{~m}^{2}\right)$, and they are out of our scope.

\section{Theoretical Justification of the Optimum Tilt Angles}

In order to evaluate the optimum longitudinal tilt angles $\beta_{M}$ and $\beta_{a}$ for the application of SSLFRs in urban areas, we first analyze their influence qualitatively.

\subsection{Influence of $\beta_{M}$ over $A$ and Influence of $\beta_{a}$ over $E$}

The way to minimize $A$ is to require the rays reflected by the mirrors in the longitudinal direction to be vertical. The greater the angle between the rays reflected by the mirrors in the longitudinal direction with the vertical, the greater the total illuminated length of the absorber tube, and, as a consequence, the greater the surface area taken by the SSLFR (see Figure 2). The angle affecting the surface area required for the installation of the SSLFR is $\beta_{M}$, whereas $\beta_{a}$ affects the energy $E$ absorbed by the absorber tube, as increasing $\beta_{a}$ causes an increase in the total illuminated length of the absorber tube, while the surface area required for the installation of the SSLFR remains constant (see Figure 3).

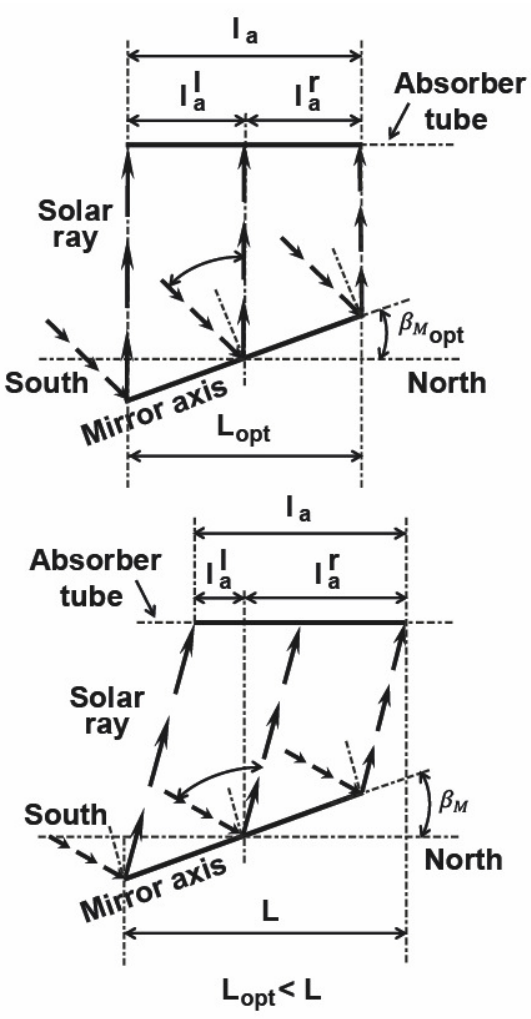

Figure 2. Influence of $\beta_{M}$. 

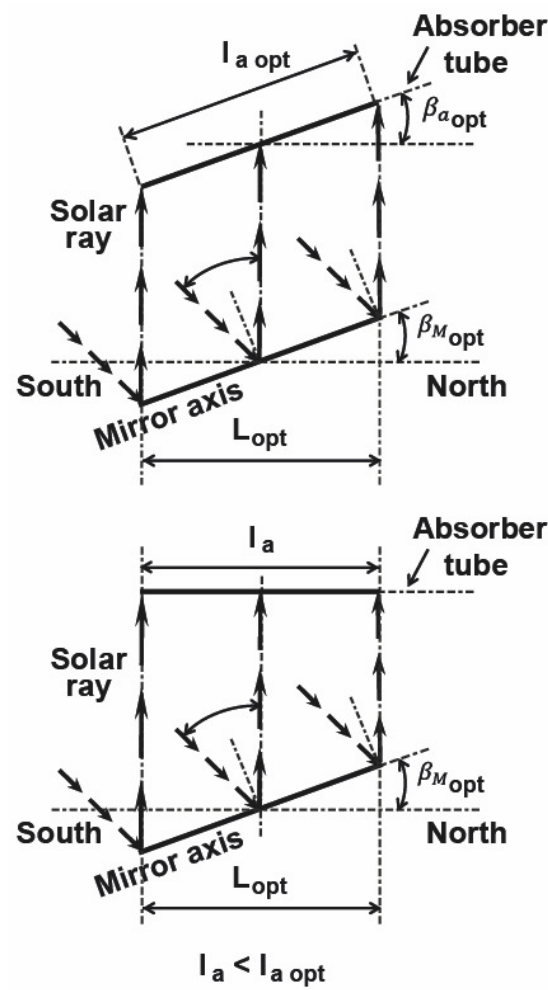

Figure 3. Influence of $\beta_{a}$.

\subsection{Calculation of the Optimum $\beta_{M}$}

Figure 4 shows the parameters involved in this study. The value of $\mu$ is:

$$
\mu=2 \beta_{M}-\theta_{z}
$$

In order to minimize the area required for the installation of the SSLFR, we shall impose that the rays reflected by the mirrors in the longitudinal direction are vertical at solar noon, which is the moment of daily maximum radiation, throughout the year, which happens if $\mu=0$ (see Figure 5). The annual mean value is then:

$$
\bar{\mu}=2 \beta_{M}-\bar{\theta}_{z \min }=0
$$

where $\bar{\theta}_{z}$ min is the annual mean value of the zenith angle of the Sun at solar noon.

The following equation expresses the height angle of the Sun $\left(\alpha_{S}\right)$ as a function of the declination, $\delta$, the latitude, $\lambda$, and the hour angle, $\omega$ :

$$
\alpha_{S}=\arcsin [\sin \delta \sin \lambda+\cos \delta \cos \lambda \cos \omega]
$$

Setting $\omega=0$ (solar noon), the solar height is maximum for a specific day ordinal $\left(n_{d}\right)$ :

$$
\alpha_{S \max }=\arcsin [\sin \delta \sin \lambda+\cos \delta \cos \lambda]
$$

Computing the sine of the solar height:

$$
\sin \alpha_{S \max }=[\sin \delta \sin \lambda+\cos \delta \cos \lambda]
$$

and applying trigonometric equalities, we get:

$$
\sin \alpha_{S \max }=\cos (\lambda-\delta)=\sin \left(\frac{\pi}{2}-(\lambda-\delta)\right)
$$




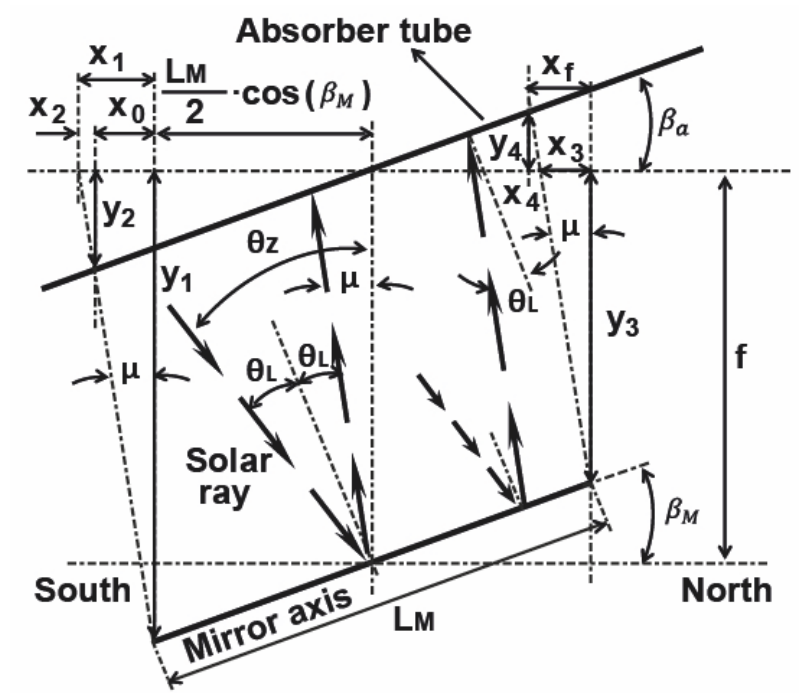

Figure 4. Schema of the longitudinal plane.

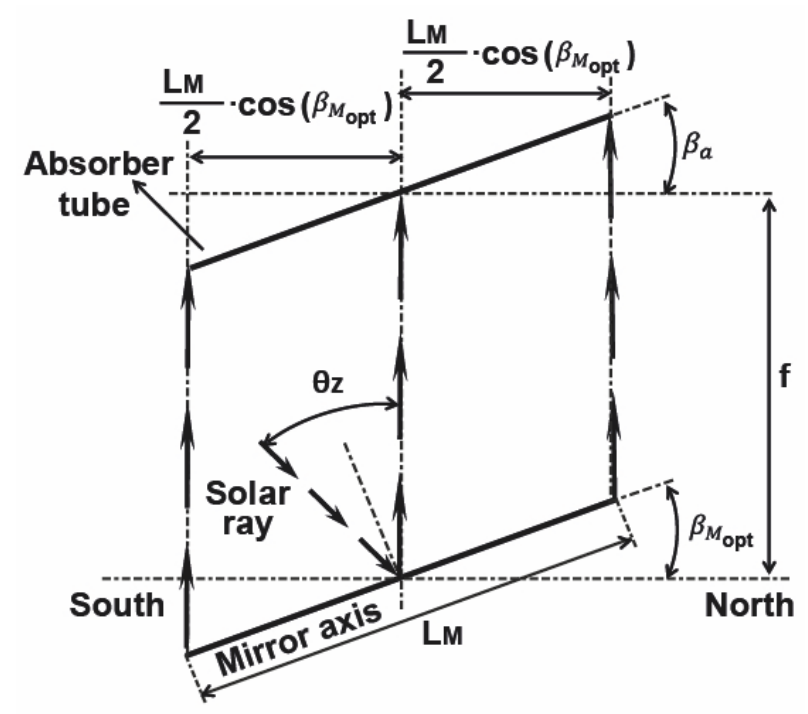

Figure 5. Case with $\mu=0$.

Thus:

$$
\alpha_{S \max }=\frac{\pi}{2}-(\lambda-\delta)
$$

The annual mean value for the height angle is then:

$$
{\overline{\alpha_{S}}}_{\max }=\frac{\sum_{n_{d}=1}^{365}\left(\frac{\pi}{2}-(\lambda-\delta)\right)}{\sum_{n_{d}=1}^{365} n_{d}}=\frac{\sum_{n_{d}=1}^{365} n_{d}\left(\frac{\pi}{2}-\lambda\right)+\sum_{n_{d}=1}^{365} \delta}{\sum_{n_{d}=1}^{365} n_{d}}
$$

Spencer [18] provides this approximate expression for the declination in rad:

$$
\begin{aligned}
\delta=0.006918-0.399912 \cos \Gamma & +0.070257 \sin \Gamma-0.006758 \cos 2 \Gamma \\
& +0.000907 \sin 2 \Gamma-0.002697 \cos 3 \Gamma+0.001480 \sin 3 \Gamma
\end{aligned}
$$

where $\Gamma$ (the day angle in rad) is:

$$
\Gamma=\left(n_{d}-1\right) \frac{2 \pi}{365}
$$


where $n_{d}$ is the ordinal of the day. The annual mean value for the declination is then:

$$
\bar{\delta}=\frac{\sum_{n_{d}=1}^{365} \delta}{\sum_{n_{d}=1}^{365} n_{d}}=0.0069(\mathrm{rad})
$$

and we shall assume it is 0 . Thus,

$$
{\overline{\alpha_{S}}}_{\max }=\left(\frac{\pi}{2}-\lambda\right)
$$

The zenith angle of the $\operatorname{Sun}\left(\theta_{z}\right)$, is also commonly used, or the complementary angle to the height angle of the $\operatorname{Sun}\left(\theta_{z}=\frac{\pi}{2}-\alpha_{S}\right)$ :

$$
\bar{\theta}_{z \min }=\frac{\pi}{2}-{\overline{\alpha_{S}}}_{\max }=\lambda
$$

Substituting Equation (15) into (4) we get:

$$
\beta_{M}=\frac{\overline{\theta_{z}} \min }{2}=\frac{\lambda}{2}
$$

which shows that the optimum tilt angle of the mobile structure depends on the place of deployment of the SSLFR.

Figure 6 shows the value of $\mu$ for depending on $\beta_{M}$ at solar noon in Almeria. Notice how for $\beta_{M}=\frac{\lambda}{2}$, we have a $\bar{\mu}$ of 0 .

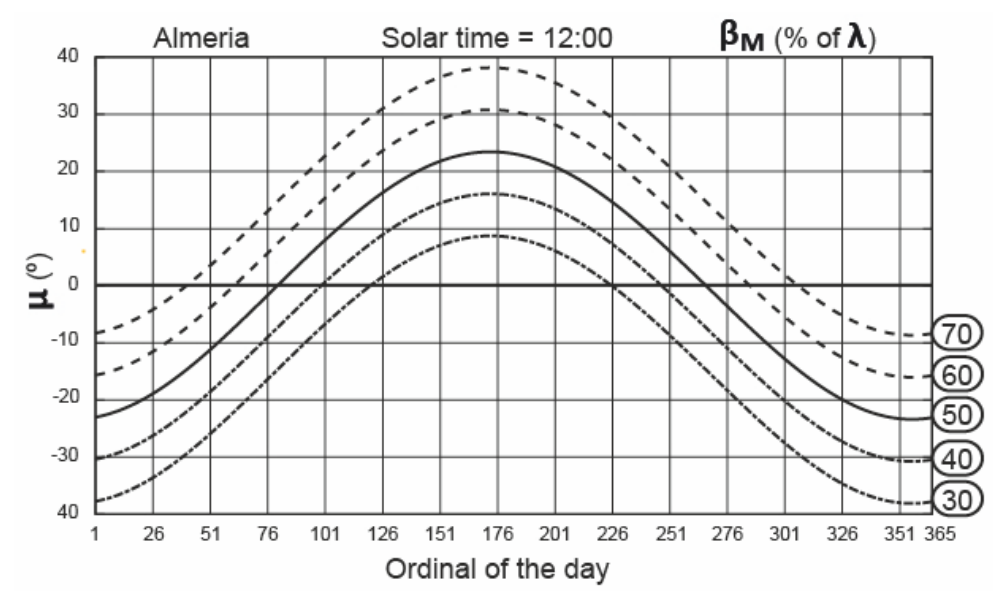

Figure 6. Value of $\mu$ for several $\beta_{M}$ values.

\subsection{Calculation of the Optimum $\beta_{a}$}

Once the optimum value of the tilt angle of the mobile structure has been determined, the left $\left(l_{a}^{l}\right)$ and right $\left(l_{a}^{r}\right)$ illuminated lengths of the absorber tube can be computed, using (31) and (32) (simply imposing $\bar{\mu}=0$ ):

$$
\begin{aligned}
& l_{a}^{l}=\frac{\frac{L_{M}}{2} \cos \beta_{M}}{\cos \beta_{a}} \\
& l_{a}^{r}=\frac{\frac{L_{M}}{2} \cos \beta_{M}}{\cos \beta_{a}}
\end{aligned}
$$

The greater $l_{a}^{l}$ and $l_{a}^{l}$ (with the restrictions on the optimum tilt angle of the mobile structure), the greater the annual total energy absorbed by the absorber tube. From Equations (17) and (18), the maximum values will be reached when the denominator is minimum, which happens (within the allowed range $\beta_{a}^{\min } \leq \beta_{a} \leq \beta_{a}^{\max }$ ) for:

$$
\beta_{a}=\lambda
$$




\section{Results and Discussion}

In this section, we verify the validity of Equations (16) and (19), using a brute-force search algorithm, and we confirm that these values cause the EAR for the SSLFR installation to be maximum.

We have discretized the time in 10 min steps. Using MATLAB routines, we have computed the following values: direct normal irradiance, optical efficiency, mirror position, and the effective area of the absorber tube. The shading, blocking, end loss effects, and end reflected light loss were also taken into account. The method presented by [19] is used to determine the hourly beam solar irradiance on a horizontal surface for the weather conditions of a particular site and for each day of the year. This method uses the satellitebased solar radiation data PVGIS (photovoltaic geographical information system) [20] for each city under study as input. Table 1 shows the parameters used in this study.

Table 1. Constant parameters in the study.

\begin{tabular}{lll}
\hline Param. & Value & References \\
\hline$n$ & 12 & {$[12,14]$} \\
$W_{M}$ & 0.06 & {$[12,14,21]$} \\
$d$ & 0.024 & {$[12,14]$} \\
$D$ & 0.0486 & {$[12,14]$} \\
$f$ & 1.5 & {$[12,14,21,22]$} \\
$L$ & 2.0 & {$[12,14]$} \\
\hline$\rho$ & 0.94 & {$[23]$} \\
$C L_{m}$ & 0.96 & {$[24]$} \\
$C L_{g}$ & 0.96 & {$[24]$} \\
$\tau$ & 0.87 & {$[25]\left(\alpha_{i} \leq 20^{\circ}\right)$} \\
$\tau$ & 0.85 & {$[25]\left(20^{\circ} \leq \alpha_{i} \leq 30^{\circ}\right)$} \\
\hline
\end{tabular}

The European Union has combined the Köppen-Geiger classification with the European Heat Index, the European Cooling Index and the nearly zero-energy buildings (NZEB) zoning to establish climatic zones with similar characteristics, shown in Table 2: Csa, temperate with dry, hot summer; $C f b$, temperate without dry season and warm summer; $D f b$, temperate continental climate/humid continental climate without dry season and with warm summer and $D f c$, cold, without dry season and with cold summer. Countries may have more than one climatic zone, and it is sometimes difficult to establish the prevailing climate classification of Köppen.

Table 2. Cities in NZEB climate zones.

\begin{tabular}{clc}
\hline Zone & \multicolumn{1}{c}{ Cities } & Köppen [26] \\
\hline Zone 1 & Athens, Larnaca-Luga-Catania-Almeria-Palermo & Csa \\
Zone 2 & Lisbon-Madrid-Marseille-Rome & $C s a / C f b$ \\
Zone 3 & Bratislava-Budapest-Ljubljana-Milan-Venice & $D f b$ \\
Zone 4 & Amsterdam-Berlin-Brussels-Copenhagen-Dublin & $C f b / D f b$ \\
Zone 5 & -London-Macon-Nancy-Paris-Prague-Warszawa & $D f c$ \\
\hline
\end{tabular}

Equations (16) and (19) have been used in five cities. The selection criteria are: different climate zones and different latitudes. Table 3 contains our choices.

A brute-force algorithm is used to verify Equations (16) and (19). The number of possible combinations is reduced by using the following known facts: (i) the available area must not exceed $10\left(\mathrm{~m}^{2}\right)$ [14]; (ii) the values of $\beta_{M}$ and $\beta_{a}$ have to be between 0 and $\lambda$. 
Table 3. Cities under study.

\begin{tabular}{clccc}
\hline Zone & \multicolumn{1}{c}{ Cities } & Latitude & Longitude & Altitude \\
\hline Zone 1 & Almeria (Spain) & $36^{\circ} 50^{\prime} 07^{\prime \prime} \mathrm{N}$ & $02^{\circ} 24^{\prime} 08^{\prime \prime} \mathrm{W}$ & $22(\mathrm{~m})$ \\
Zone 2 & Rome (Italy) & $41^{\circ} 53^{\prime} 30^{\prime \prime} \mathrm{N}$ & $12^{\circ} 30^{\prime} 40^{\prime \prime} \mathrm{E}$ & $52(\mathrm{~m})$ \\
Zona 3 & Budapest (Hungary) & $47^{\circ} 29^{\prime} 52^{\prime \prime} \mathrm{N}$ & $19^{\circ} 02^{\prime} 23^{\prime \prime} \mathrm{E}$ & $111(\mathrm{~m})$ \\
Zone 4 & Berlin (Germany) & $52^{\circ} 31^{\prime} 27^{\prime \prime} \mathrm{N}$ & $13^{\circ} 24^{\prime} 37^{\prime \prime} \mathrm{E}$ & $37(\mathrm{~m})$ \\
Zone 5 & Helsinki (Finland) & $60^{\circ} 10^{\prime} 10^{\prime \prime} \mathrm{N}$ & $24^{\circ} 56^{\prime} 07^{\prime \prime} \mathrm{E}$ & $26(\mathrm{~m})$ \\
\hline
\end{tabular}

Figures 7-11 contain the results of the search. They show the EAR values in Almeria, Rome, Budapest, Berlin, and Helsinki, respectively, and confirm that the equations we propose are correct for all those locations. Thus, we have verified that the following:

(1) By keeping $\beta_{a}$ constant when $\beta_{M}=\frac{\lambda}{2}$, one obtains the greatest $E A R$.

(2) For a fixed $\beta_{M}$, an increase in $\beta_{a}$ causes an increase in $E A R$.

(3) The maximum value of $E A R$ is always for $\beta_{M}=\frac{\lambda}{2}$ and $\beta_{a}=\lambda$.

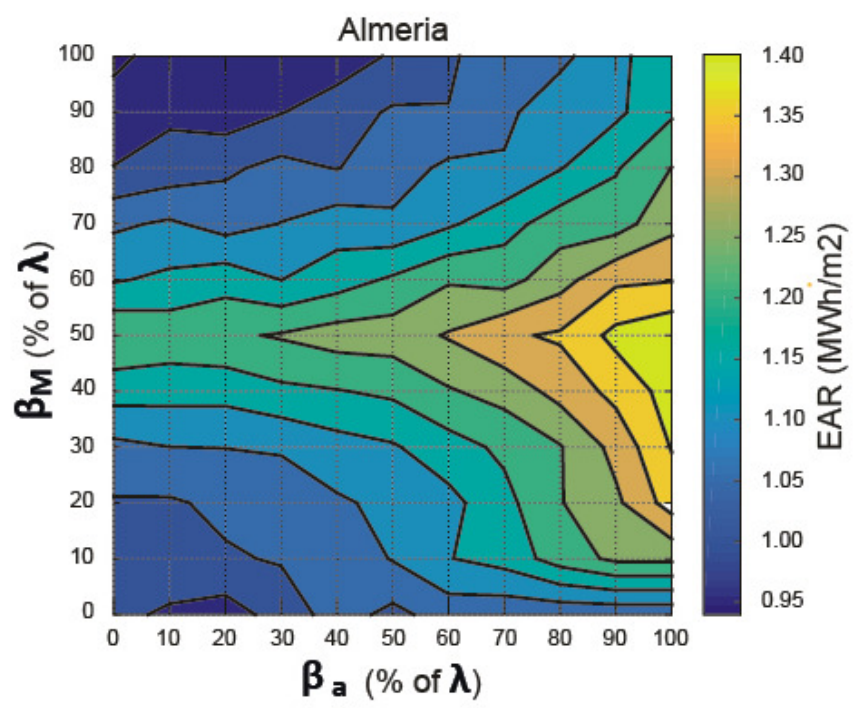

Figure 7. EAR in Almeria.

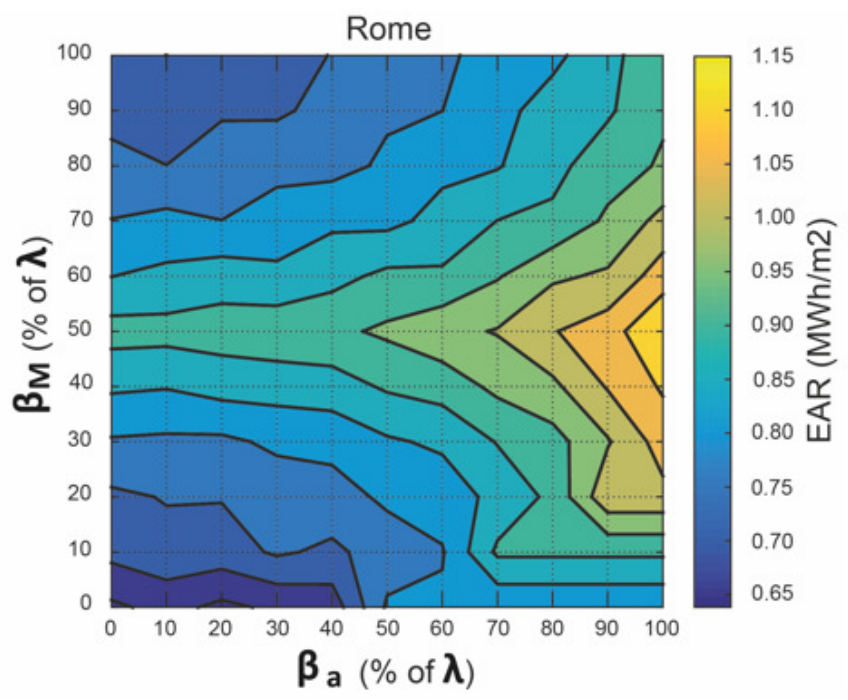

Figure 8. EAR in Rome. 


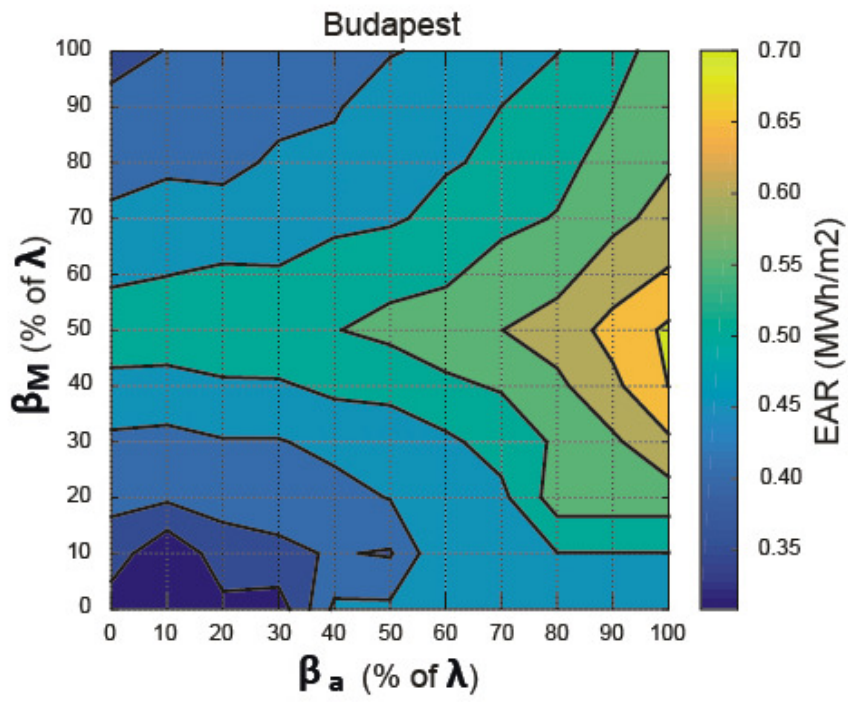

Figure 9. EAR in Budapest.

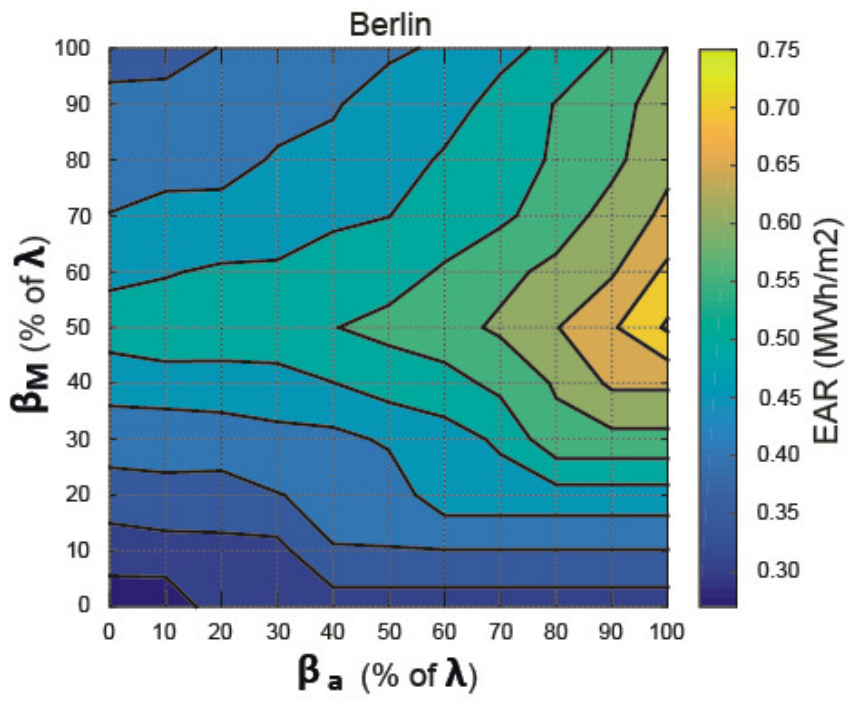

Figure 10. EAR in Berlin.

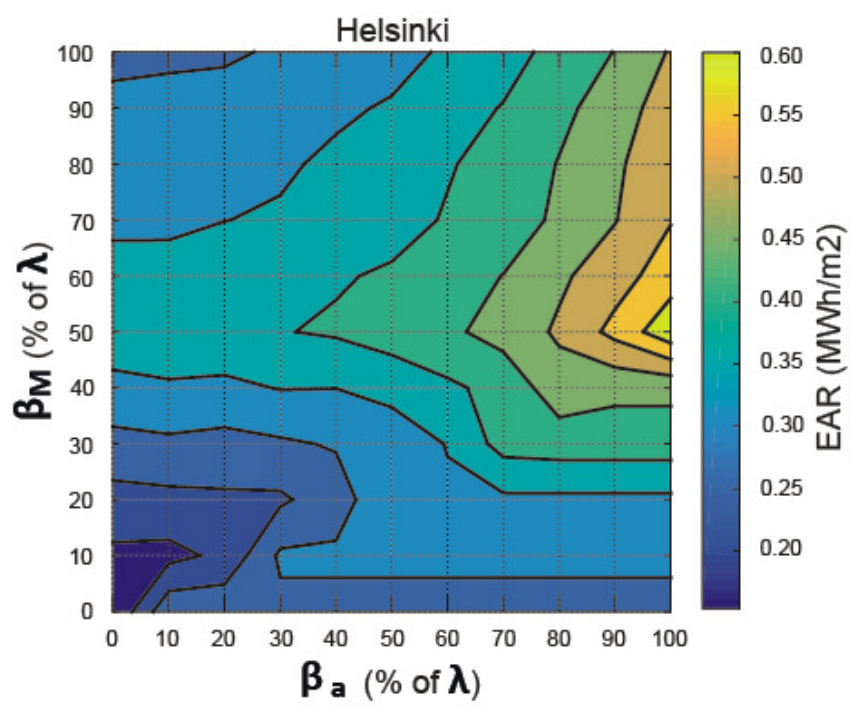

Figure 11. EAR in Helsinki. 
The results show that the optimum longitudinal tilt angle of the mobile structure is half the latitude of the geographic location and that the optimum longitudinal tilt angle of the secondary reflector system is equal to the latitude, and we have verified this result for five cities of the European Union, each belonging to one of the five European climate zones.

Figure 12 shows the relation between the value of $E A R$ and the maximum value of $E A R$ for fixed $\beta_{M}=\frac{\lambda}{2}$ and varying $\beta_{a}$. Deviations in relation to the optimum $\beta_{a}$ have a higher influence as the city's latitude is higher. As the $\beta_{a}$ deviations increase, the $E A R$ becomes lower, getting its minimum value for $\beta_{a}=0\left(^{\circ}\right)$. In Helsinki, $60 \%$ of the optimum $E A R$ is obtained for the minimum value. Values of $E A R$ between $70 \%$ and $87 \%$ of the optimum $E A R$ are obtained in the other cities.

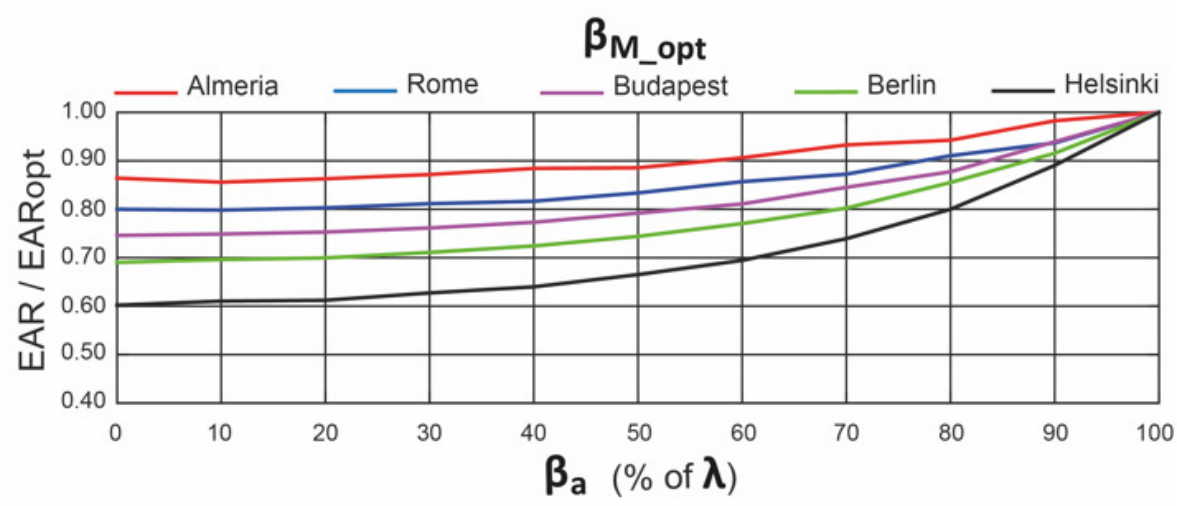

Figure 12. Influence of $\beta_{a}$.

Figure 13 shows the relationship between the value of $E A R$ and the maximum value of $E A R$ for fixed $\beta_{a}=\lambda$ and varying $\beta_{M}$. Deviations in relation to the optimum $\beta_{M}$ have a higher influence as the city's latitude is higher, for values of $\beta_{M}$ lower than the optimum value of $\beta_{M}$.

Notice that the influence of $\beta_{M}$ is greater than the influence of the $\beta_{a}$.

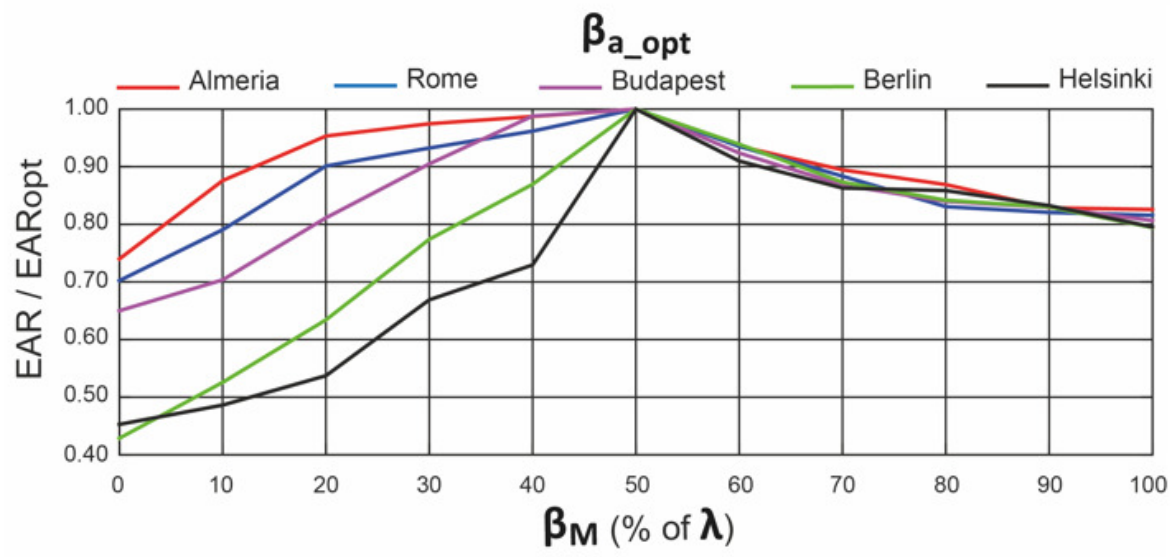

Figure 13. Influence of $\beta_{M}$.

\section{Conclusions}

For urban application of SSLFRs, the area required for its installation is important, and it is affected by the tilt angles of the mobile structure and the secondary reflector system. A methodology for calculating the optima of both angles is presented. Once these are determined, the algorithm proposed in [12] for calculating the optimal values of the longitudinal position and length of the absorber tube can be applied. Optimum tilt angles have been evaluated taking into account the different geographical locations. A brute-force search algorithm is used to verify the results, and several tables of different tilt angles are presented. The following are the key observations of our study: (1) The optimum tilt 
angles of the SSLFR depend on the geographical location. (2) The optimum tilt angle of the mobile structure is $\lambda / 2$ for any geographical location. (3) The optimum tilt angle of the secondary reflector system is $\lambda$ for any geographical location. (4) For a fixed $\beta_{M}=\frac{\lambda}{2}$ and $\beta_{a}$, the deviations with respect to the optimum $\beta_{a}$ have a higher influence as the city's latitude is higher. (5) For a fixed $\beta_{a}=\lambda$ and $\beta_{M}$, the deviations in relation to the optimum $\beta_{M}$ have a higher influence as the city's latitude is higher, for values of $\beta_{M}$ smaller than the optimum. (6) The influence of $\beta_{M}$ is greater than the influence of the $\beta_{a}$.

These contributions are useful for many possible future studies related to concentrated photovoltaic systems based on SSLFRs, as our system has no moving parts, which reduces costs and power consumption.

\section{Annex}

In this Annex we collect all the formulae required to compute the $E A R$ :

$$
E A R=\frac{1}{A} \sum_{n_{d}=1}^{365}\left[\int_{0}^{24}\left(\sum_{i=0}^{2 \cdot n} D N I^{n_{d}}\left(T_{S}\right) \cdot \eta_{o p t} \cdot I A M_{i}^{n d}\left(T_{S}\right) \cdot A_{e f f i}^{n_{d}}\left(T_{S}\right)\right) d T_{S}\right]
$$

The area $A$ required for the SSLFR installation is:

$$
A=W \cdot L
$$

The mirror field width $W$ is:

$$
W=2 \cdot n \cdot\left(W_{M}+d\right)+W_{M}
$$

while the reflector length $L$ can be computed with the following relations:

(1) If $L_{a}^{l} \cdot \cos \left(\beta_{a}\right) \leq \frac{1}{2} \cdot L_{M} \cdot \cos \left(\beta_{M}\right)$ and $L_{a}^{r} \cdot \cos \left(\beta_{a}\right) \leq \frac{1}{2} \cdot L_{M} \cdot \cos \left(\beta_{M}\right)$ then:

$$
L=L_{M} \cdot \cos \left(\beta_{M}\right)
$$

(2) If $L_{a}^{l} \cdot \cos \left(\beta_{a}\right)>\frac{1}{2} \cdot L_{M} \cdot \cos \left(\beta_{M}\right)$ and $L_{a}^{r} \cdot \cos \left(\beta_{a}\right) \leq \frac{1}{2} \cdot L_{M} \cdot \cos \left(\beta_{M}\right)$ then:

$$
L=L_{a}^{l} \cdot \cos \left(\beta_{a}\right)+\frac{1}{2} \cdot L_{M} \cdot \cos \left(\beta_{M}\right)
$$

(3) If $L_{a}^{l} \cdot \cos \left(\beta_{a}\right) \leq \frac{1}{2} \cdot L_{M} \cdot \cos \left(\beta_{M}\right)$ and $L_{a}^{r} \cdot \cos \left(\beta_{a}\right)>\frac{1}{2} \cdot L_{M} \cdot \cos \left(\beta_{M}\right)$ then:

$$
L=\frac{1}{2} \cdot L_{M} \cdot \cos \left(\beta_{M}\right)+L_{a}^{r} \cdot \cos \left(\beta_{a}\right)
$$

The parameter DNI is the direct normal irradiance. The method presented by [19] was used to estimate it. The parameter $\eta_{o p t}$ is the total optical yield, which is calculated considering the reflectivity of the mirrors $(\rho)$, the cleanliness factors of the mirror $\left(C I_{m}\right)$ and of the glass covering the secondary absorber $\left(C I_{g}\right)$, the transmissivity of this glass $(\tau)$, and the absorptivity of the material of which the absorber tube is made $\left(\alpha_{b}\right)$ :

$$
\eta_{\text {opt }}=\left(\rho \cdot C I_{m}\right) \cdot\left(\tau \cdot C I_{g} \cdot \alpha_{b}\right)
$$

The parameter $I A M_{i}$ expresses the variation in the optical performance of an SSLFR for varying ray incidence angles, for the $i$-th mirror, [12]:

$$
\begin{gathered}
\text { IAM }_{i}=\left[C_{L}^{2}+C_{T i}^{2}+2 \cdot C_{L} \cdot C_{T i} \cdot \cos \widehat{C_{L} C_{T i}}\right]^{1 / 2} ; 0 \leq i \leq 2 n \\
C_{L}=\cos \gamma_{S} \cdot \cos \theta_{L} ; C_{T i}=\frac{\cos \alpha_{S} \cdot \sin \gamma_{S} \cdot \cos \theta_{i}}{\sin \theta_{t}} ; 0 \leq i \leq 2 n
\end{gathered}
$$

The value $A_{e f f i}$ is the effective area of the absorber tube of the $i$-th mirror, which is actually illuminated. This parameter is calculated considering the total illuminated length 
of the absorber tube $\left(l_{a}\right)$ and the length of the circumference illuminated on the absorber tube by the $i$-th mirror $\left(l_{\text {ciai }}\right)$ :

$$
A_{\text {effi }}=l_{\text {ciai }} \cdot l_{a} ; 0 \leq i \leq 2 n
$$

The value of $l_{a}$ is the sum of the left illuminated length of the absorber tube $\left(l_{a}^{l}\right)$, and the right illuminated length of the absorber tube $\left(l_{a}^{r}\right)[12]$ :

$$
\begin{gathered}
l_{a}=l_{a}^{l}+l_{a}^{r} \\
l_{a}^{l}=\frac{1}{\cos \beta_{a}}\left[\frac{\left[f+\frac{L_{M}}{2}\left[\sin \beta_{M}-\cos \beta_{M} \tan \beta_{a}\right]\right] \tan \mu}{1+\tan \beta_{a} \tan \mu}+\frac{L_{M}}{2} \cos \beta_{M}\right] \\
l_{a}^{r}=\frac{1}{\cos \beta_{a}}\left[\frac{L_{M}}{2} \cos \beta_{M}-\frac{\left[f+\frac{L_{M}}{2}\left[\cos \beta_{M} \tan \beta_{a}-\sin \beta_{M}\right]\right] \tan \mu}{1+\tan \beta_{a} \tan \mu}\right]
\end{gathered}
$$

The parameter $l_{\text {ciai }}$ is computed considering the width on the absorber tube illuminated by the $i$-th mirror $\left(W_{a i}\right)$, the angle between the vertical at the focal point and the line connecting the center point of each mirror to the focal point $\left(\alpha_{i}\right)$, and the diameter of the absorber tube $(D)[12]$ :

$$
l_{\text {ciai }}= \begin{cases}\frac{\pi D}{2} & \text { if } W_{a i} \cos \alpha_{i}>D \\ D \arcsin \left(\frac{W_{a i}}{D}\right) & \text { if } W_{a i} \cos \alpha_{i} \leq D\end{cases}
$$

where $W_{a i}$, the width on the absorber tube illuminated by the $i$-th mirror, is given by:

$$
W_{a i}=W_{M} \cdot\left[\cos \beta_{i} \pm \sin \beta_{i} \tan \alpha_{i}\right] ; 0 \leq i \leq 2 n
$$

$\alpha_{i}$ being the angle between the vertical at the focal point and the line connecting the center point of each mirror to the focal point and $\beta_{i}$ the tilt of the $i$-th mirror. The sign \pm means for the left side and + for the right side. The angle $\alpha_{i}$ is given by:

$$
\alpha_{i}=\arctan \left[\frac{i \cdot\left(W_{M}+d\right)}{f+D / 2}\right] ; 1 \leq i \leq n
$$

Finally, $T_{S}$ is the solar time, $n$ is the number of mirrors on each side of the central mirror, $n_{d}$ is the ordinal of the day, and $A$ is the area required for the SSLFR installation. This parameter is calculated considering the mirror field width $(W)$ and the reflector length (L) [13].

Author Contributions: Conceptualization: A.B. and L.B., investigation: C.B.-C. and J.A.F.R.; wrote and final editing: A.B., L.B., C.B.-C. and J.A.F.R. All authors have read and agreed to the published version of the manuscript.

Funding: This research was funded by the Business Chair: "Training and immersion in sustainable development" of the University of Oviedo.

Institutional Review Board Statement: Not applicable.

Informed Consent Statement: Not applicable.

Data Availability Statement: Not applicable.

Acknowledgments: The authors wish to thank Laudino Rodríguez, head of the CIFP-Mantenimiento y Servicios a la Producción vocational training school in La Felguera, Asturias, Spain, for his work of building the prototype for the design presented in this paper.

Conflicts of Interest: The authors declare no conflict of interest. 


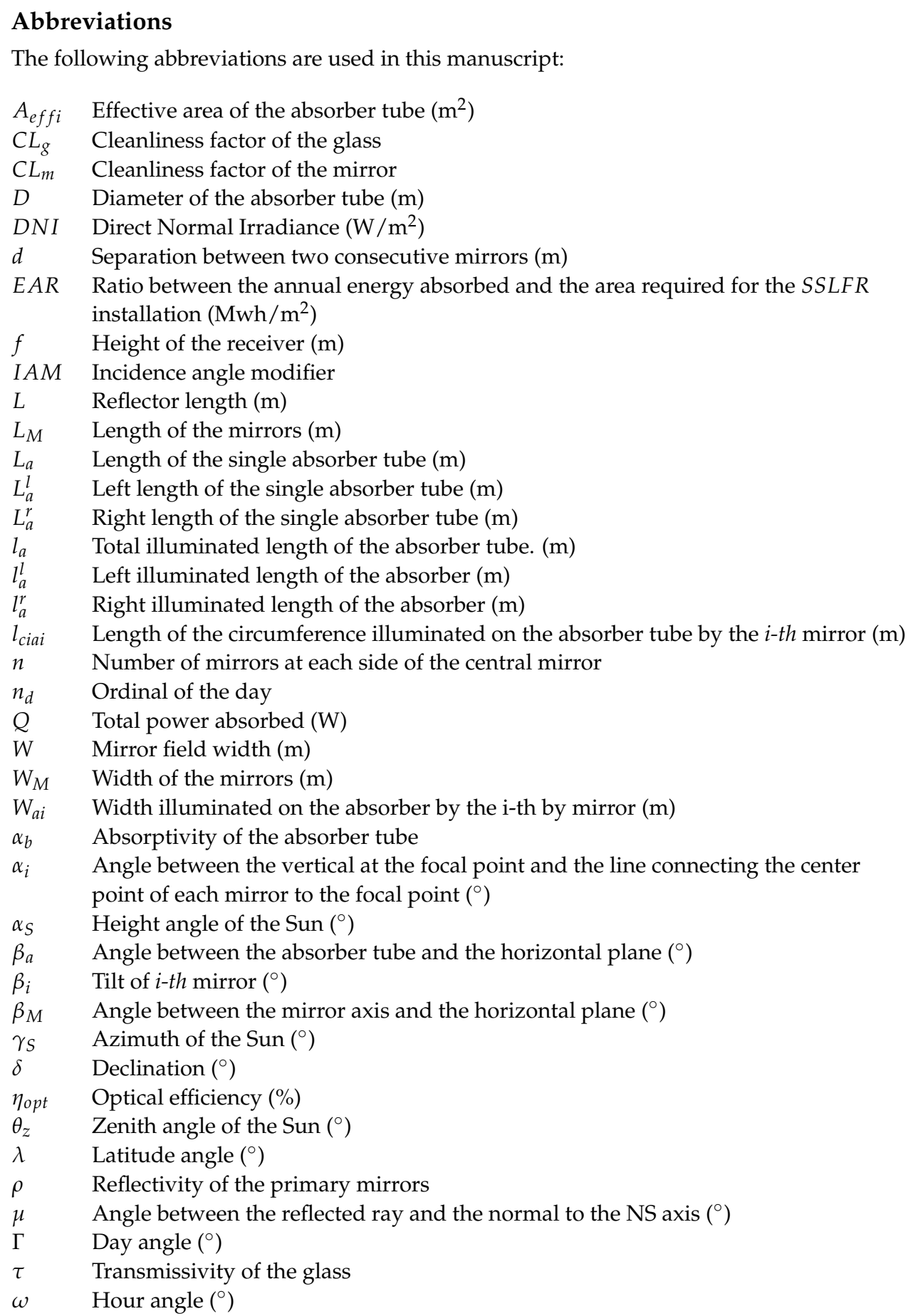

\section{References}

1. EUROSTAT. Eurostat, Energy Statistics-An Overview. 2017. Available online: https://ec.europa.eu/eurostat/statisticsexplained/index.php?title14Energy_statistics_-_an_overview\#Energy_intensity (accessed on 15 April 2021).

2. European Commission. Energy-Heating and Cooling. 2018. Available online: https://ec.europa.eu/energy/en/topics/ energyefficiency/heating-and-cooling (accessed on 15 April 2021).

3. European Council Report. 2019. Available online: http://www.consilium.europa.eu/uedocs/cms_data/docs/pressdata/en/ec/ 145397.pdf (accessed on 15 April 2021).

4. Buker, M.S.; Riffat, S.B. Building integrated solar thermal collectors-A review. Renew. Sustain. Energy Rev. 2015, 51, 327-346. [CrossRef]

5. Mokhtar, G.; Boussad, B.; Noureddine, S. A linear Fresnel reflector as a solar system for heating water: Theoretical and experimental study. Case Stud. Therm. Eng. Case 2016, 8, 176-186. [CrossRef] 
6. Serag-Eldin, M.A. Thermal design of a roof-mounted CLFR collection system for a desert absorption chiller. Int. J. Sustain. Energy 2014, 33, 506-524. [CrossRef]

7. Velázquez, N.; García-Valladares, O.; Sauceda, D.; Beltrxaxn, R. Numerical simulation of a Linear Fresnel Reflector Concentrator used as direct generator in a Solar-GAX cycle. Energy Convers. Manag. 2010, 51, 434-445. [CrossRef]

8. Zhou, L.; Li, X.; Zhao, Y.; Dai, Y. Performance assessment of a single/double hybrid effect absorption cooling system driven by linear Fresnel solar collectors with latent thermal storage. Sol. Energy 2017, 151, 82-94. [CrossRef]

9. Montenon, A.C.; Papanicolas, C. Economic assessment of a PV hybridized linear Fresnel collector supplying air conditioning and electricity for buildings. Energies 2021, 14, 131. [CrossRef]

10. Boito, P.; Grena, R. Application of a fixed-receiver linear Fresnel reflector in concentrating photovoltaics. Sol. Energy 2021, 215, 198-205. [CrossRef]

11. Barbón, A.; Sánchez-Rodríguez, J.A.; Bayxoxn, L.; Barbxoxn, N. Development of a fiber daylighting system based on a small-scale linear Fresnel reflector: Theoretical elements. Appl. Energy 2018, 212, 733-745. [CrossRef]

12. Barbón, A.; Barbxoxn, N.; Bayxoxn, L.; Otero, J.A. Optimization of the length and position of the absorber tube in small-scale Linear Fresnel Concentrators. Renew. Energy 2016, 99, 986-995. [CrossRef]

13. Barbón, A.; Bayxoxn, L.; Bayxoxn-Cueli, C.; Barbxoxn, N. A study of the effect of the longitudinal movement on the performance of small scale linear Fresnel reflectors. Renew. Energy 2019, 138, 128-138. [CrossRef]

14. Barbón, A.; Bayxoxn-Cueli, C.; Bayxoxn, L.; Rodríguez, L. Investigating the influence of longitudinal tilt angles on the performance of small scale linear Fresnel reflectors for urban applications. Renew. Energy 2019, 143, 1581-1593. [CrossRef]

15. Nixon, J.D.; Davies, P.A. Construction and experimental study of an elevation linear Fresnel reflector. J. Sol. Energy Eng. 2016, 138, 031001. [CrossRef]

16. Pulido-Iparraguirre, D.; Valenzuela, L.; Serrano-Aguilera, J.J.; Fernández-García, A. Optimized design of a Linear Fresnel reflector for solar process heat applications. Renew. Energy 2019, 131, 1089-1096. [CrossRef]

17. Barbón, A.; Sánchez-Rodríguez, J.A.; Bayxoxn, L.; Bayxoxn-Cueli, C. Cost estimation relationships of a small-scale linear Fresnel reflector. Renew. Energy 2019, 134, 1273-1284. [CrossRef]

18. Spencer, J.W. Fourier series representation of the position of the sun. Search 1971, 2, 172.

19. Barbón, A.; Ayuso, P.F.; Bayxoxn, L.; Fernández-Rubiera, J.A. Predicting beam and diffuse horizontal irradiance using Fourier expansions. Renew. Energy 2020, 154, 46-57. [CrossRef]

20. PVGIS. Joint Research Centre (JRC). 2021. Available online: http://re.jrc.ec.europa.eu/pvg_tools/en/tools.html\#PVP (accessed on 15 April 2021).

21. Zhu, Y.; Shi, J.; Li, Y.; Wang, L.; Huang, Q.; Xu, G. Design and thermal performances of a scalable linear Fresnel reflector solar system. Energy Convers. Manag. 2017, 146, 174-181. [CrossRef]

22. Zhu, Y.; Shi, J.; Li, Y.; Wang, L.; Huang, Q.; Xu, G. Design and experimental investigation of a stretched parabolic linear Fresnel reflector collecting system. Energy Convers. Manag. 2016, 126, 89-98. [CrossRef]

23. Duffie, J.A.; Beckman, W.A. Solar Engineering of Thermal Processes, 4th ed.; John Wiley \& Sons: New York, NY, USA, 2013.

24. Sharma, V.; Khanna, S.; Nayak, J.K.; Kedare, S.B. Effects of shading and blocking in compact linear fresnel reflector field. Energy 2016, 94, 633-653. [CrossRef]

25. Theunissen, P.H.; Beckman, W.A. Solar transmittance characteristics of evacuated tubular collectors with diffuse back reflectors. Sol. Energy 1985, 35, 311-320. [CrossRef]

26. Kottek, M.; Grieser, J.; Beck, C.; Rudolf, B.; Rubel, F. World map of the Köppen-Geiger climate classification updated. Meteorol. Z. 2006, 15, 259-263. [CrossRef] 